$\xi=1$ 国

\title{
Design of a compact reconfigurable antenna with triple band switchable characteristics
}

\author{
P. Pardhasaradhi' ${ }^{1}$, B.T.P. Madhav ${ }^{*}$, D. Rajendra Kamal ${ }^{1}$, M. Chinna Somaiah ${ }^{1}$, \\ Ch. Gayathri' ${ }^{1}$ M. Koteswara Rao ${ }^{1}$, T. Anilkumar ${ }^{1}$ \\ ${ }^{I} A R C$, Department of ECE, Koneru Lakshmaiah Education Foundation, Guntur, AP, India \\ *Corresponding author E-mail: btpmadhav@kluniversity.in
}

\begin{abstract}
Antennas with reconfigurable functionality is the mostly preferred one in the antennas field. In such scenario, a work is presented in this article proposing a frequency reconfigurable antenna with a compact PIFA kind of structure. The antenna structure has the folded radiating structure and embedded with some lumped resistance and distributed capacitance, inductance for providing the impedance matching across desired bands for wireless communication. Further, the switching elements (PIN diodes-BAR64-02V) are inserted in the gap between the long-meandered line structure for attaining the switchable characteristics among single band $(0.68-0.98 \mathrm{GHz})$, dual band $(0.70$ - $0.96 \mathrm{GHz}, 2.26-2.65 \mathrm{GHz})$, and triple band $(0.69-0.99 \mathrm{GHz}, 1.89-2.78 \mathrm{GHz}, 3.64-4.1 \mathrm{GHz}) \mathrm{respectively}$. The impedance bandwidth is considered according to $\mathrm{S} 11<-6 \mathrm{~dB}$ criteria for the mobile communication applications. The proposed antenna is suitable for smartphone, laptop and portable devices with GSM/PCS/WCDMA/UMTS/LTE communication applications.
\end{abstract}

Keywords: Reconfigurable antenna; switchable; PIN diodes; PIFA; folded patch.

\section{Introduction}

The term reconfigurability in the antenna design terminology refers the changing the various properties of the antenna by a control signal which be of the electrical form, mechanical or optical. The properties of the antenna fundamentally remind the frequency or operating band characteristics, radiation pattern and polarization of the antenna depending on which the reconfigurability is applied. These kind of features, when incorporated in antenna design will makes the antenna multi-functional and this minimizes the necessity of using the multiple antennas in a particular communication system.

To obtain the multiband functionality is essential for designing the frequency reconfigurable antennas. Some of the earlier proposed methods to achieve multiband characteristics are presented in [1, 2], with feeding post and shorting post. The loop-element is contributing the lower-frequency band whereas the adjacent higher modes are producing the higher-band. The concentric external metallic ring structures a central internal semicircular patch and shorted to ground plane in the PIFA mode is used in [3]. In [4,5], the switchable operation between wideband and multiband and low-and high bands have been established respectively. The single continuous loop element was given with three connections to feed point and two shorting points and operated in PIFA and loop modes for reconfigurable purpose in [6]. Tunable capacitance method is applied for getting switchable response among mobile communication bands in [7] and a cross shaped sleeve arm and the modified feed structure for a miniaturized microstrip square slot is proposed in [8]. The S-shaped radiating structure is divided into several isolated strips which are then connected through the switching elements can be seen in [9], which is intended to obtain reconfigurability. The analysis of diode positions and the switching operation is presented in [10], when the diodes are placed between the PIFA and spiral structures incorporated in the antenna. Switching elements controls the T-shaped stepped impedance resonator and a parallel stub loaded resonator in [11] and give frequency switchable performance. In [12], two PIN diodes are used to control the radiating element with ON/OFF biasing states in three modes in turn the antenna is made to operate in Inverted-F antenna (IFA) mode, monopole mode and loop mode for switching over various mobile communication bands. A reconfigurable antenna is designed in [13], with bowtie slot antenna configuration i.e., fed with $\mathrm{CPW}$ feed which made the antenna able to switch between single, dual and triple bands. The stepped slot incorporated in the rectangular patch which divides into two halves and these portions are connected with the PIN diodes and the triple band switchable characteristics have obtained as discussed in [14].

In this work, a reconfigurable antenna design is presented for multiband switchable functionality. The PIFA kind of radiating structure is used and developed with the lumped elements like capacitive, inductive, resistive elements with the design aspects which are discussed in Section 2. The effect of varying the distributed capacitance structure, effect of inserting switching elements and their placement to achieve the frequency switchable function are explained with thorough parametric study in Section 3. The simulation results are presented in Section 4 in terms of frequency vs reflection coefficient parameter, surface current distributions, radiation characteristics at three different switching cases and concluded in Section 5. 


\section{Antenna Design}

The design of the proposed antenna is discussed in this section. It is printed on the FR4 substrate, which is having a relative permittivity of 4.4. It is an electric insulator with great flame resistance and the name "FR" stands for flame retardant. It is highly recommendable for fabrication purpose because of its ability to maintain mechanical and electrical insulating properties irrespective of the environmental conditions. The FR4 substrate extends over a width of $35 \mathrm{~mm}$ and length of $10 \mathrm{~mm}$ and thickness of $0.8 \mathrm{~mm}$. Height of the substrate represents the thickness of the substrate used for fabrication. An extra copper metal plate is attached with the one's etched on to the substrate and is bent backwards in and inverted-L shape as shown in the Fig.1(b) and this is done in order to improve the achievable bandwidth. This bent metal plate covers an area of $35 \times 8 \mathrm{~mm}^{2}$. Wireless communication techniques are well observed in portable and handheld devices and such devices require the components inside them to be compact and the same applies for the antenna being used. In order to maintain this compact nature of the antenna the excess metal plate attached on top the substrate is bent backwards with a gap of $3 \mathrm{~mm}$ from the substrate and parallel to it. Ground plane with a width of $200 \mathrm{~mm}$ and a length of $150 \mathrm{~mm}$ is considered and connected to the pre-etched ground plane (having dimensions $1 \times 15 \mathrm{~mm}^{2}$ ) on the substrate.

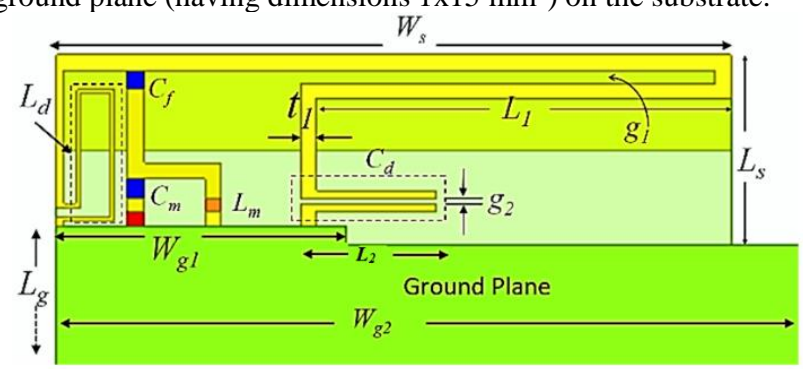

(a) Antenna Front View

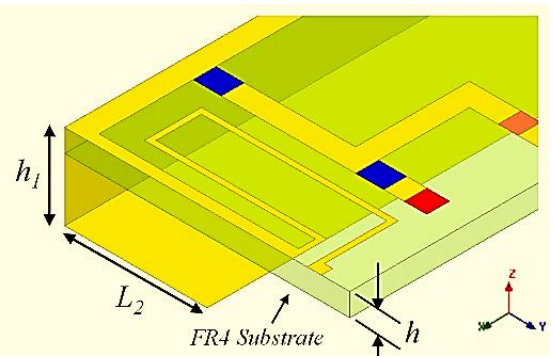

(b) Antenna perspective view

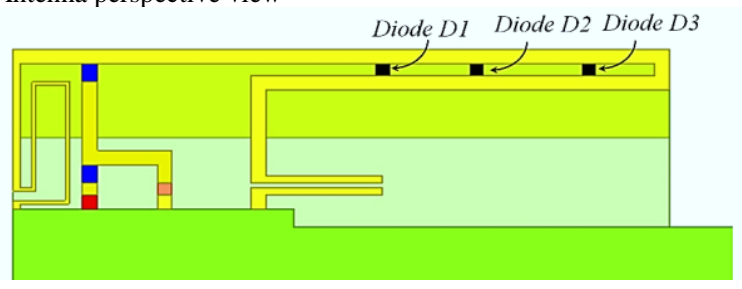

(c) Design showing different placement of diodes D1, D2 and D3

Fig. 1 Geometry of Proposed Reconfigurable antenna

Table 1: Dimensions of proposed antenna

\begin{tabular}{l|c|c|c|c|c|c}
\hline Parameter & $W_{s}$ & $W_{g 1}$ & $W_{g 2}$ & $t_{l}$ & $h$ & $h_{l}$ \\
\hline Value $(\mathrm{mm})$ & 35 & 15 & 200 & 0.8 & 0.3 & 3 \\
\hline Parameter & $L_{s}$ & $L_{g}$ & $L_{l}$ & $L_{2}$ & $g_{1}$ & $g_{2}$ \\
\hline Value $(\mathrm{mm})$ & 10 & 150 & 21.5 & 5 & 0.7 & 0.3 \\
\hline
\end{tabular}

Apart from the extended bent metal plate and the ground plane there the etched portion on the substrate has some important parts in it which play a key role in obtaining the desired output and one among them is the feeding strip it is the small $h$-shaped portion on the substrate which is connected to the ground pad on the substrate.
The lumped port is used as connection between this small $h$ shaped portion and the ground pad and since the lumped port is used to give the required energy supply for the device to work effectively. This feeding strip also contains some passive elements like the capacitors and the inductors these passive elements provide the necessary support in order to achieve the required bands and also switching between these bands or the modes of operation. As shown in the Fig.1(a) there are two capacitors ' $\boldsymbol{C}_{\boldsymbol{f}}$ ' and ' $\boldsymbol{C}_{\boldsymbol{m}}$ ' with capacitances $0.6 \mathrm{pF}$ and $2.2 \mathrm{pF}$ respectively and also have an inductor ' $\boldsymbol{L} \boldsymbol{m}$ ' with an inductance of $9.5 \mathrm{nH}$. This feeding strip is connected to another key part which is important to radiate the signal and this is called as the radiating strip. The radiating strip is the long strip along the width of the substrate on the top which takes a hair-pin like turn and moves downward and looks like an inverted-F shape. The inverted-F portion is of $7.5 \mathrm{~mm}$ length and $0.4 \mathrm{~mm}$ in width the coupling gap between them is of $0.3 \mathrm{~mm}$ and this portion acts like a distributed capacitor just like when two current conductor plates are separated by a certain coupling distance acts like a capacitor. This distributed capacitor has a capacitance ' $\boldsymbol{C}_{\boldsymbol{f}}$ ' of about $0.3 \mathrm{pF}$. The other important part of the etched portion on substrate is the shorting strip, which is a loop like structure on the left most part of the substrate. This structure is used to ground the combined portion of feeding and the radiating strip to the ground pad. The shorting strip has a loop like structure running over a length of $17 \mathrm{~mm}$ and a width of $0.2 \mathrm{~mm}$ this loop acts like a distributed inductor ' $\boldsymbol{L} d$ ' with an inductance of about $5 \mathrm{nH}$. All these parts are etched onto the FR4 substrate as per the dimensions mentioned in the Table 1 . The entire design of the antenna is performed in ANSYS Electronic Desktop 17.2 3D EM HFSS tool.

\section{Parametric Study}

Parametric study is a kind of approach in understanding the characteristics of the model under different circumstances mostly done in order to analyze and study the data when its values are varied in regular partitions. These variations are done in the form of change in dimensions of the structures or patches designed on the substrate apart from the dimensions specified for a desirable result. In this work, parametric study on the reconfigurable antenna is done in three aspects as discussed in the following. These parameters play a very crucial role in determining the outcome. In each of these variations a single variable parameter has been put through parametric analysis and an extensive study of the characteristics exhibited by the antenna are discussed as below.

\section{Case I: Effect of varying ' $\mathrm{g}_{2}$ ' parameter for changing the gap of the distributed capacitor}

The gap shown in the Fig. 1(a) between the strips of the distributed capacitor is called as coupling gap since it compels the structure to act like a capacitor with a capacitance of around $0.3 \mathrm{pF}$ for a gap of $0.3 \mathrm{~mm}$. this gap is determined in the design with the variable ' $g_{2}$ ' and by altering this parameter the response in the reflection coefficient vs frequency curve varies.

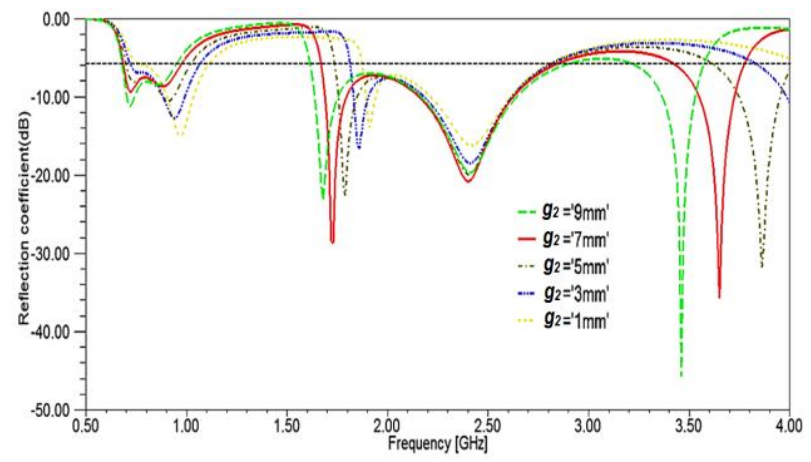

Fig. 2: Effect of variation of parameter ' $g_{2}$ ' on $\mathrm{S}_{11}$ characteristics. 
Here the gap between the plates of the distributed capacitor varies the effective capacitance of the structure and this inflicts the outcome in way which is represented in the Fig. 2. The output of the desired antenna is represented by a solid red line and this is for the gap of $7 \mathrm{~mm}$, one can observe that the dip in the resonating curve of the middle wide band is maximum when gap value is set to $7 \mathrm{~mm}$ and all the other curves are decreasing gradually in comparison to the desired one.

\section{Case II: Effect of varying " $\mathrm{L}_{2}$ " parameter for changing the length of the strips of distributed capacitor}

The parameter ' $\mathrm{L}_{2}$ ' is assigned for the length of the plates of the distributed capacitor as shown in Fig. 1(a) and this parameter is varied in order to vary the length of the plates of the capacitor which in turn effects the capacitance of the distributed capacitor and this again effects the frequency vs reflection coefficient curve. So in order to study the various characteristics exhibited by the change in the length of the plates a parametric analysis is done on the $\mathrm{L}_{3}$ parameter and the result in shown in the Fig. 3 the desired result is represented with solid red line were as the rest are ruled out for slight unwanted characteristics.

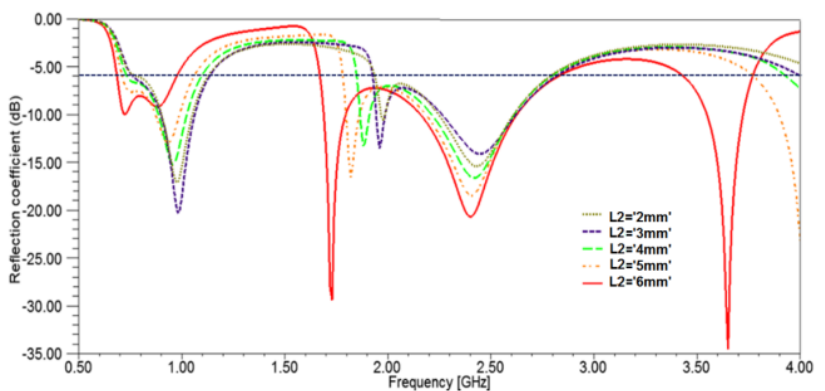

Fig. 3: Effect of variation of parameter ' $L 2$ ' on $\mathrm{S}_{11}$ characteristics

Case III: Effect of varying " $L_{1}$ " parameter for changing the length of the hair-pin bend like structure in the radiating strip

The length of the hair-pin bend like structure is represented by the Parameter ' $L_{l}$ ' and the parametric analysis is done on it and the desired value is found at the ' $L_{l}$ ' value of $21.5 \mathrm{~mm}$. There is no significant variations in the lower band. But in the middle band the bandwidth is enhanced and also the dip of the curve representing the reflection coefficient is greatest for ' $L_{l}$ ' value of $21.5 \mathrm{~mm}$ which makes it the best pick among the other and beyond the value of $21.5 \mathrm{~mm}$ the structure cannot extend since it just moves out of the substrate boundary and it is necessary for this hair-pin bend like structure to be on the substrate premises in order for the antenna to function with novel characteristics as shown in Fig. 4.

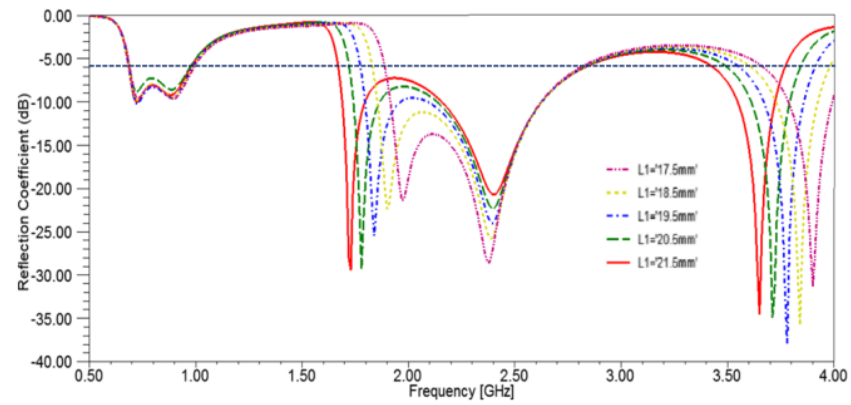

Fig. 4: Effect of variation of parameter ' $L_{l}$ ' on $\mathrm{S}_{11}$ characteristics.

\section{Results and Discussion}

The simulation results obtained for placing diodes at different positions are discussed briefly in order to study the characteristics of the antenna at different conditions and also how the property of reconfigurability is being incorporated into the antenna design in a sequential manner. Three diode positions are specifically studied and discussed. The diode positions are as shown in the Fig. 1(c) and also several observations have been made with respect to the current distribution for different aspects.

\subsection{Reflection coefficient characteristics}

The operating bands and their ranges are determined by the reflection coefficient level below $-6 \mathrm{~dB}$. All the bands that cross this $6 \mathrm{~dB}$ mark are considered as the operating bands and there are three operating bands operating in wide band frequencies and they are shown in the Fig.7. The lower operating band ranges from 0.68 $\mathrm{GHz}$ to $0.97 \mathrm{GHz}$ and has a resonating frequency of $0.73 \mathrm{GHz}$. The mid-band frequencies range of operation is from $1.67 \mathrm{GHz}$ to $2.83 \mathrm{GHz}$ and has a resonance frequency of $1.73 \mathrm{GHz}$ and finally the higher band has an operating frequency range of $3.43 \mathrm{GHz}$ to $3.77 \mathrm{GHz}$ and has a resonant frequency of $3.65 \mathrm{GHz}$. The diodes placed at different positions in between the gap of the radiating arms enables us to understand that as the diode moves from the position Diode D1 to the end of the bending structure changes the response and we can observe that the number of operating bands and bandwidth are increasing as it moves to right towards the end which contains a hair-pin like bend.

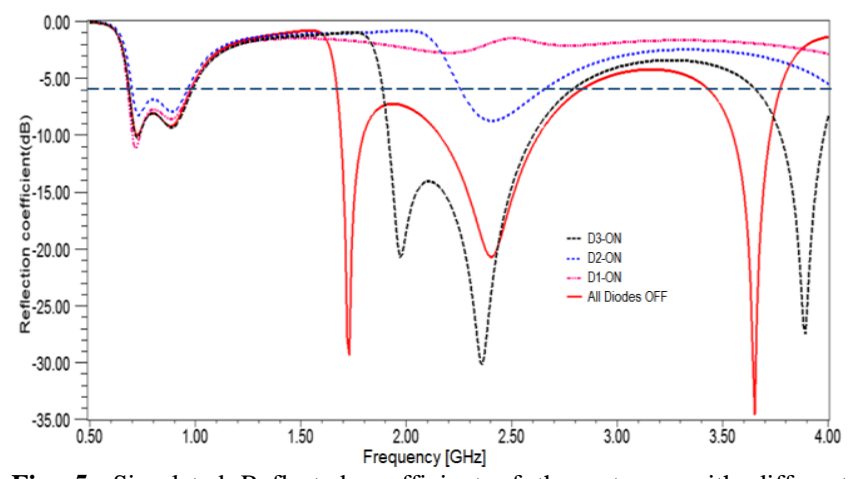

Fig. 5: Simulated Reflected coefficient of the antenna with different switching cases.

The antenna structure with the CPW feed and having the extended feed line operates from 8.1-10.4 GHz band, whereas the closed ground structure which is incorporated in the second iteration creates the deeper resonance at $9.8 \mathrm{GHz}$ and operates from 8.5 $10.45 \mathrm{GHz}$. The third iteration in which the ground planes with the asymmetrical lengths and appended the lower rectangular strip. By adding the structure, the antenna tends to operate from $8.9 \mathrm{GHz}$ $11.3 \mathrm{GHz}$ and an additional operating band is observed from 13.8 $\mathrm{GHz}$, extends beyond $15 \mathrm{GHz}$. In this case, the primary operating band which has been existing since earlier iterations is decaying and the second band is shifted from $15 \mathrm{GHz}$ to $12.75 \mathrm{GHz}$. The antenna iteration-4 thus operates from $11.7 \mathrm{GHz}$ to $13.8 \mathrm{GHz}$. In the fifth iteration of the antenna design the extension of vertical feedline with a larger rectangular strip on its top is provided. This decreased the obtained resonance frequency towards $12.2 \mathrm{GHz}$ and the primary, secondary operating bands are merged together thus creating wider band width from $9.3-13 \mathrm{GHz}$. The proposed antenna iteration covers maximum of $\mathrm{X}$-band spectrum.

\section{Case I: All diodes 'D1', 'D2' and 'D3' are reverse biased}

The desired antenna does not have any diodes in between the length of the radiating arm which is bent along the width of the 
substrate as shown in Fig.1(a). The proposed antenna works in triple wide band frequencies as shown in Fig.7. Out of the triple wide band the first lower band has frequency of operation from $0.69 \mathrm{GHz}$ to $0.97 \mathrm{GHz}$ and has a resonance frequency of $0.73 \mathrm{GHz}$ then the middle band has the frequency of operation from 1.67 $\mathrm{GHz}$ to $2.83 \mathrm{GHz}$ and has a resonance frequency of $1.73 \mathrm{GHz}$ and the absence of diodes with a single long hair-pin bend structure causes it to operate in an extra third wide band which is not seen in any of the three S11 results representing the three diode positions which makes this the desirable antenna. The third band has an operation frequency ranging from $3.43 \mathrm{GHz}$ to $3.77 \mathrm{GHz}$ and has a resonating frequency of $3.65 \mathrm{GHz}$.

\section{Case II: The diode 'D1' alone is forward biased}

The diode D1 alone is turned ON while the remaining are kept in OFF condition compels the device to work in the lower wide band range with the frequency of operation ranging from $0.68 \mathrm{GHz}$ to $0.98 \mathrm{GHz}$ and at this the antenna has a resonant frequency of 0.72 GHz. When we observe the Fig. 5 we can see that the graph is operating only in a single wide band which in comparison to the original desired output signal shown is Fig. 4 and this is due to the shorting of the continuous line of the radiating arm causing an alternate route for the current flow and the $S_{11}$ curve changes as the diodes position shifts towards right side.

\section{Case III: The diode 'D2' alone is forward biased}

When the diode D2 alone is turned ON while the remaining are kept in OFF condition, reflection coefficient vs frequency graph changes and now this positioning of the diode enables the antenna to work in two wide band operating frequencies. The lower band operating frequency ranges from $0.70 \mathrm{GHz}$ to $0.96 \mathrm{GHz}$ and with a resonant frequency of $0.73 \mathrm{GHz}$ and the middle band ranging from $2.26 \mathrm{GHz}$ to $2.65 \mathrm{GHz}$ and has resonant frequency of 2.40 $\mathrm{GHz}$.

\section{Case IV: The diode ' $\mathrm{D3}$ ' alone is forward biased}

The diode D3 alone is turned ON while the remaining are kept in OFF condition. The diode being placed in this position enables the antenna to operate in triple wide band. Here the lower band frequency operation is ranging from $0.69 \mathrm{GHz}$ to $0.99 \mathrm{GHz}$ and has a resonant frequency of $0.72 \mathrm{GHz}$ and the middle band has the operating frequency range starting from $1.89 \mathrm{GHz}$ to $2.78 \mathrm{GHz}$ and has a resonant frequency of $2.36 \mathrm{GHz}$ and the higher band operating frequency range is unclear from this observation making its partial presence insignificant.

\subsection{Surface Current Distribution Characteristics}

The surface current distribution patterns are generated through simulation which are obtained at corresponding resonant frequencies at various switching cases.

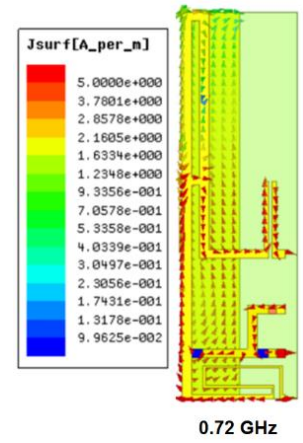

(a) diode $\mathrm{D} 1$ alone $\mathrm{ON}$
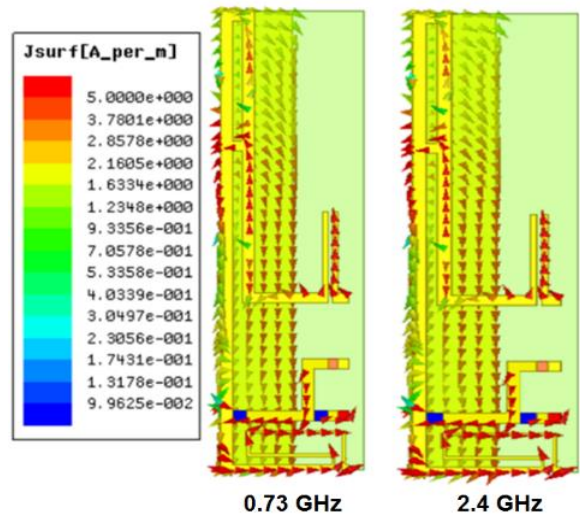

(b) diode $\mathrm{D} 2$ alone $\mathrm{ON}$

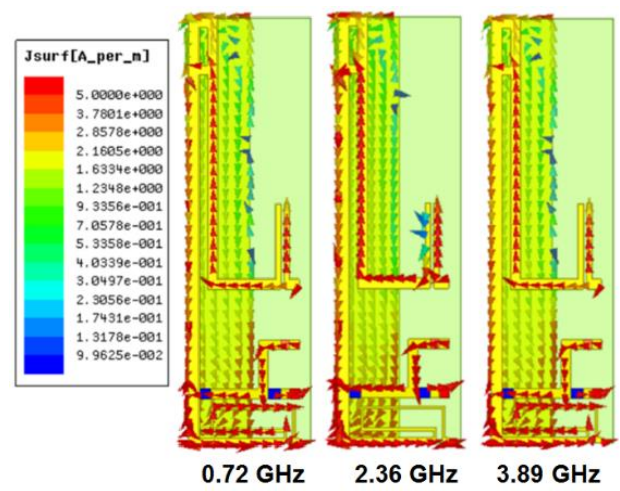

(c) diode D3 alone ON

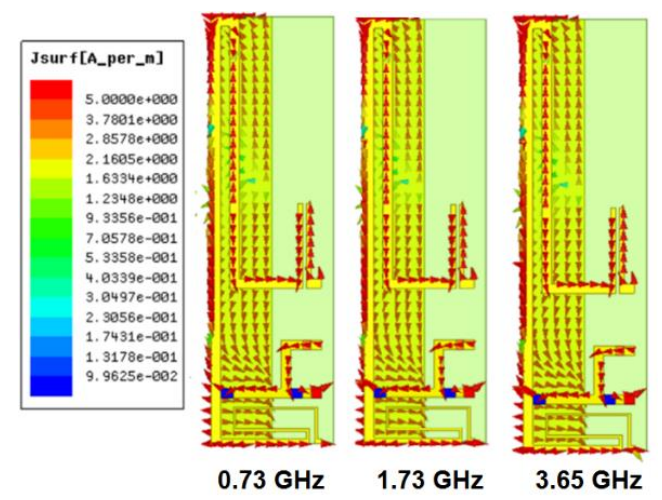

(d) All Diodes are OFF

Fig. 6: Simulated Surface current distributions on the proposed reconfigurable antenna.

In Fig. 6, the patterns are obtained at $0.72 \mathrm{GHz}$ which is shown in Fig. 6(a). The diode D1 when forward biased, establishes the current path which is shown with greater amplitude region. In Fig. 6(b) the distributed impedance and capacitance paths are more significant resonant structures at $0.73 \mathrm{GHz}$ and $2.4 \mathrm{GHz}$. The surface current distribution pattern when the diode D3 is turned $\mathrm{ON}$ whereas the remaining diodes are turned OFF at which the antenna operates at three bands. The effective current element length follows the path which is shown in Fig. 6(c) with greater intensity path in which the h-shaped feed path and the distributive elements accomodates greater current desnities. All of the diodes when turned OFF the bent structure holds the maxium distribution of current elements and the maximum current path traverses along the hair-pin like structure which can be seen in Fig. 6(d). 


\subsection{Radiation Patterns of the Proposed Reconfigurable} Antenna
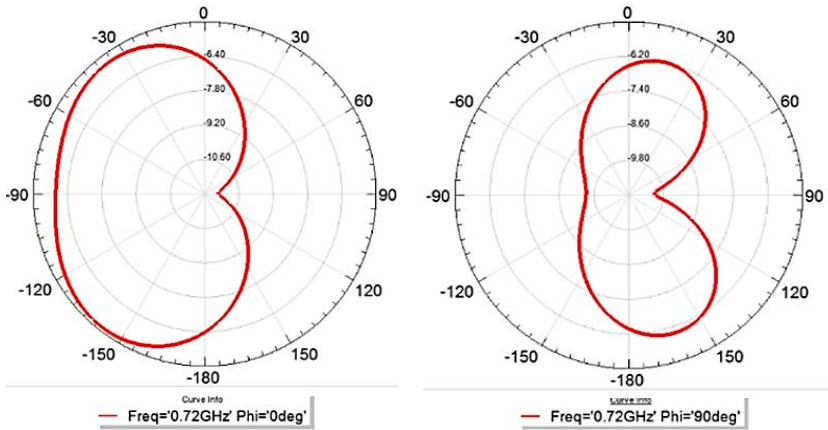

(a) diode $\mathrm{D} 1$ alone $\mathrm{ON}$
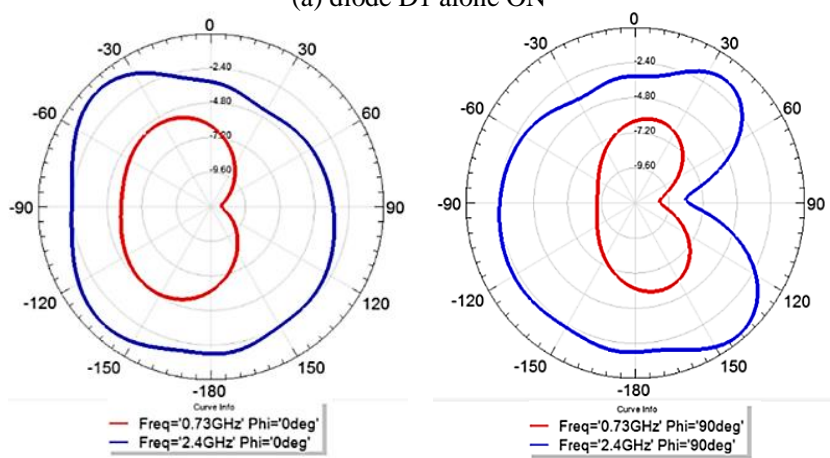

(b) diode $\mathrm{D} 2$ alone $\mathrm{ON}$
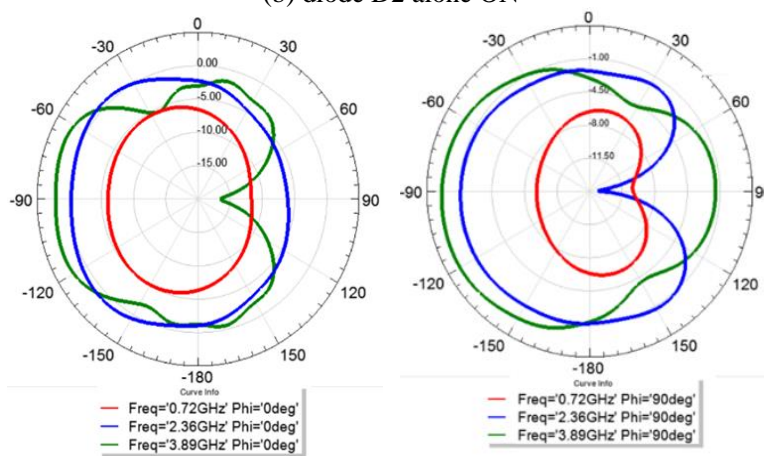

(c) diode $\mathrm{D} 3$ alone $\mathrm{ON}$
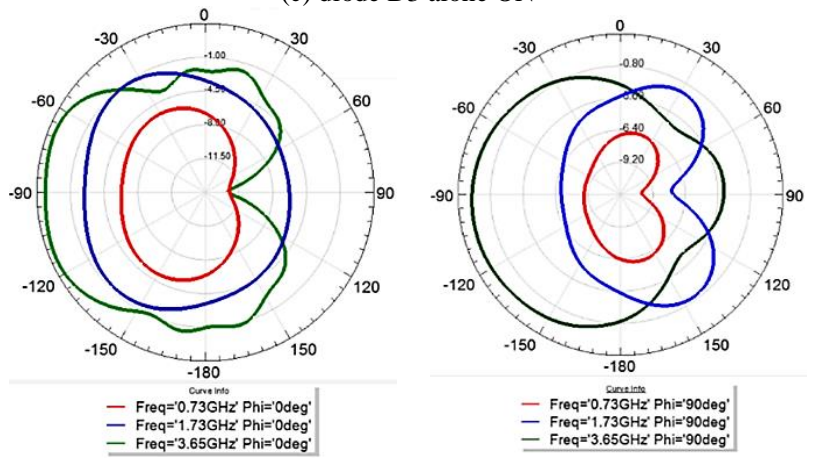

(d) All Diodes are OFF

Fig. 6: Simulated Radiation patterns of the proposed reconfigurable antenna (E-plane and H-plane)

The radiation characteristics of the proposed reconfigurable antenna are presented in two of its principal planes namely E-plane and H-plane as shown in Fig. 7. The antenna operates in three bands, the radiation patterns of the corresponding resonances obtained at different switching cases are in good correlation with the patterns obtained when all diodes are reverse biased. At low frequencies, the patterns resemble the dipole kind of radiation with limited gain. The gain of the antenna is gradually increased as the occurrence of mid-band and higher bands respectively.
Table 3: Comparison of different switchable conditions of the antenna

\begin{tabular}{c|c|c|c|c}
\hline $\begin{array}{c}\text { Switchable } \\
\text { iteration }\end{array}$ & $\begin{array}{c}\text { Operating } \\
\text { bands (GHz) }\end{array}$ & $\begin{array}{c}\text { Resonant } \\
\text { Frequencies }\end{array}$ & $\begin{array}{c}\text { Peak } \\
\text { Gain } \\
(\mathrm{dB})\end{array}$ & $\begin{array}{c}\text { Radiation } \\
\text { Efficiency } \\
(\%)\end{array}$ \\
\hline Without & $0.69-0.97$ & 0.73 & -5.15 & 88.89 \\
diodes & $1.67-2.83$ & 1.73 & -5.46 & 89.64 \\
& $3.43-3.77$ & 3.65 & 2.08 & 83.09 \\
\hline D1-ON & & & & \\
D2-OFF & $0.68-0.98$ & 0.72 & -5.09 & 90.49 \\
D3-OFF & & & & \\
\hline D1-OFF & $0.70-0.96$ & 0.73 & -4.86 & 91 \\
D2-ON & $2.26-2.65$ & 2.40 & 1.24 & 89.73 \\
D3-OFF & $0.69-0.99$ & 0.72 & -5.06 & 89.91 \\
\hline D1-OFF & $1.89-2.78$ & 2.36 & 1.26 & 98 \\
D2-OFF & $3.64-4.1$ & 3.89 & 2.60 & 85.94 \\
D3-ON & & \multicolumn{2}{|c}{}
\end{tabular}

\section{Conclusion}

In this work, an antenna inverted-F configuration and with looplike structure is proposed. The radiating element has appended with the bent metallic plane and the large ground plane is used so that it can be accommodate the smart phone, tablet, laptop devices. The diodes incorporated in the gap existing in the hair-pin type bend structure and these diodes when individually turned ON the switching from single band to triple band functionality is established across single band $0.68-0.98 \mathrm{GHz}$, dual bands from $0.70-$ $0.96 \mathrm{GHz}, 2.26-2.65 \mathrm{GHz}$, triple bands ranging from $0.69-0.99$ $\mathrm{GHz}, 1.89-2.78 \mathrm{GHz}$ and $3.64-4.1 \mathrm{GHz}$ showing the antenna functional in LTE 700 / GSM 950 / CDMA 2000 / LTE 2300/2500 / ISM 2.4 G / LTE 42/43 services. The gain of the antenna in the lower most band is $-5.06 \mathrm{~dB}$ and attained a value of $1.26 \mathrm{~dB}$ and $2.6 \mathrm{~dB}$ in the triple band of operation. This mid-band gain is improved when compared with the case when no diodes are connected. In each case the antenna has good radiation efficiency more than $80 \%$.

\section{Acknowledgement}

The authors deeply express their gratitude to ALRC Research Centre, Department of ECE, Koneru Lakshmaiah Education Foundation for their encouragement during this work. Further, Madhav would like to express his gratitude to Department of Science and Technology, India through grant ECR / 2016 / 000569 , EEQ / 2016 / 000604 and FIST grant SR / FST / ETI-316 / 2012.

\section{References}

[1] Jung, B., Rhyu, H., Lee, Y.-J., Harackiewicz, F. J., Park, M.-J. and Lee, B. (2006), Internal folded loop antenna with tuning notches for GSM/GPS/DCS/PCS mobile handset applications. Microw. Opt. Technol. Lett. 48, 1501-1504.

[2] Yu, B.-k., Jung, B., Lee, H.-J., Harackiewicz, F. J. and Lee, B. (2006), A folded and bent internal loop antenna for GSM/DCS/PCS operation of mobile handset applications. Microw. Opt. Technol. Lett. 48, 463-467.

[3] M. Ng Mou Kehn, Ó. Quevedo-Teruel and E. Rajo-Iglesias. (2011), Reconfigurable Loaded Planar Inverted-F Antenna Using Varactor Diodes. IEEE Antennas and Wireless Propag. Lett. 10, 466-468.

[4] H. F. Abutarboush et al. (2012), A Reconfigurable Wideband and Multiband Antenna Using Dual-Patch Elements for Compact Wireless Devices. IEEE Trans. on Antennas and Propag. 60(1), 36-43.

[5] Y. Sung. (2014), Multi-band reconfigurable antenna for mobile handset applications. IET Microw., Antennas \& Propag. 60(1), 36-43.

[6] Sung, Y. (2014), A frequency-reconfigurable antenna for internal mobile handset applications. Microw. Opt. Technol. Lett. 56, 1366-1371.

[7] Hwang, S.-G., Yoon, C., Yoon, I. S., Chares, L., Park, C. S., Kim, W.-S., Lee, H.-C. and Park, H.-D. (2015), A reconfigurable 
mobile antenna for multiband operation using PIN-diode. Microw. Opt. Technol. Lett. 57, 406-409.

[8] M. Borhani, P. Rezaei and A. Valizade. (2016), Design of a Reconfigurable Miniaturized Microstrip Antenna for Switchable Multiband Systems. IEEE Antennas and Wireless Propag. Lett. $15,822-825$.

[9] Sreenivasa Rao, D. et al., (2016), Microstrip parasitic strip loaded reconfigurable monopole antenna. ARPN Journal of Engg. Appl. Sciences. 11(19), 11589-11594.

[10] Madhav B.T.P. et al., (2017), A Frequency Reconfigurable Spiral F-Shaped Antenna for Multiple Mobile Applications. Lecture Notes in Elect. Engg. 471, 571-580.

[11] Monika, M. et al., (2017), Coplanar waveguide FED multimode resonant switchable antenna. Int. J. Pure and Appl. Mathematics. 117(18), 75-79.

[12] Zhang X, Tian M, Zhan A, Liu Z, Liu H. (2017), A frequency reconfigurable antenna for multiband mobile handset applications. Int. J. RF Microw. Comp. Aided Eng. 27(9), e21143.

[13] Mansoul A, Seddiki ML. (2018), Multiband reconfigurable Bowtie slot antenna using switchable slot extensions for $\mathrm{WiFi}, \mathrm{Wi}$ MAX, and WLAN applications. Microw. Opt. Technol. Lett. 60, 413-418.

[14] Tumati V.R., Cheruku J. (2018). Design and Study of Frequency Reconfigurable Antenna for Wireless Applications. In: Satapathy S., Bhateja V., Chowdary P., Chakravarthy V., Anguera J. (eds) Proceedings of 2nd International Conference on MicroElectronics, Electromagnetics and Telecommunications. Lecture Notes in Elec. Eng., Springer, 434 